\title{
A Hong Kong Miracle of a Different Kind
}

Dung Kai-cheung's writing/action and Xuexi niandai (The Apprenticeship)

\section{David Der-Wei Wang}

Translator. Caroline Mason

\section{OpenEdition}

\section{Journals}

\section{Electronic version}

URL: https://journals.openedition.org/chinaperspectives/5393

DOI: 10.4000/chinaperspectives.5393

ISSN: 1996-4617

\section{Publisher}

Centre d'étude français sur la Chine contemporaine

\section{Printed version}

Date of publication: 1 January 2011

Number of pages: $80-85$

ISSN: 2070-3449

Electronic reference

David Der-Wei Wang, "A Hong Kong Miracle of a Different Kind", China Perspectives [Online], 2011/1 |

2011, Online since 30 March 2014, connection on 19 May 2022. URL: http://journals.openedition.org/ chinaperspectives/5393; DOI: https://doi.org/10.4000/chinaperspectives.5393

(c) All rights reserved 


\title{
A Hong Kong Miracle of a Different Kind
}

\author{
Dung Kai-cheung's writing/action and Xuexi niandai (The Apprenticeship)
}

\section{DAVID DER-WEI WANG*}

T he first part of Dung Kai-cheung's (董啓章) Ziranshi sanbuqu (自然史 三部曲, Natural History Trilogy) appeared in 2005. Over the past six years he has published Part 1, Tiangong Kaiwu: Xuxu ruzhen (天工開 物・棚棚如真, Works and Creation:Vivid and Lifelike), Part 2, Shijian fanshi: Yaci zhi guang (時間繁史・覀瓷之光, Histories of Time: The Lustre of Mute Porcelain); and, most recently, the first section of Part 3, Wuzhong yuanshi: Beibei chongsheng (物種源始・貝貝重生, The Origin of Species: Beibei is Reborn), which has the subtitle "Xuexi niandai" (學習年代, The Apprenticeship). (1) The trilogy has yet to be completed, but its length is already quite breath-taking. Part 1 contains 300,000 characters, Part 2,600,000, and the first volume of Part 3,520,000. The second and final volume of Part 3 is expected to contain 600,000 characters.

This is already far longer than a standard novel, but Dung seems not yet to have finished what he set out to do. What is the subject matter that impels him to write like this? The term "trilogy" brings to mind the roman-fleuve, and revolutionary romances such as Ba Jin's Torrents trilogy and Shih Shu-ching's Hong Kong trilogy. The history of China in the twentieth century was so turbulent that it seems difficult to convey its vicissitudes fully unless by writing at length, with each book taking up where the previous one leaves off. But Dung's trilogy does not focus on the history of the Chinese nation; his intention is to write about a particular "natural history," and a glance at the titles of his works alone is enough to indicate that the space-time coordinates in his fiction, and the organisation of his characters and stories, obviously run counter to the "joys and sorrows" formula of the traditional trilogy.

But Dung is not what is known today as a post-modernist writer, either. He demonstrates consummate skill in his use of contemporary narrative techniques, from collage and misplacement to parody, yet he has no intention of writing "playful" fiction. He deconstructs genders, values, and concepts that we never question, while at the same time pondering the possibility of constructing "the origin of species." He is especially mindful of the dialectical relationship between the fictional and the real, and of the ethical significance of writing. In this, Dung is actually taking on quite a "classical" responsibility.

Even more intriguingly, the environment that Dung creates is not mainland China or Taiwan, but Hong Kong. Hong Kong is not known for its literature, but in the past few decades many writers there have been quietly engaging in pure literary creation, and with great success. Dung is significant not only because he is content with his isolation there, but also because he can thus take advantage of it and work against prevailing trends. Drawing on this isolated setting, he keeps doggedly to his intended course, and creates an imaginary space entirely different from that found in the literature of either mainland China or Taiwan. In a very particular sense, his works are an echo of the perceptual structure known as "Hong Kong."

\section{From Body to City: Mapping the borders of nature and culture}

Dung Kai-cheung has long been interested in the idea of the origin of species. His first story, "Xixiliya" (Cecilia), published in 1992, already shows signs of this. A young office worker, oblivious to a female colleague's secret love for him, becomes infatuated with an armless plastic mannequin on display in the window of a clothes shop. Through a woman who works in the shop he sends her love letters, and the shop assistant takes it upon herself to reply on behalf of the mannequin, choosing the name Cecilia for her (or herself). A highly eccentric emotional relationship develops between the three of them. The story concludes with the clothes shop going out of business, but since the story of Cecilia has begun, it now has the opportunity to evolve. "What else can I do but go on writing your name and your story?" (2) In this story we can discern many of the topics that occur in Dung's later fiction, among them the themes of creation and invention, reality and desire, performance and gender; and we also see characters similar to those who subsequently appear - a steady stream of female objects, for example Xuxu and Beibei, have emerged since Cecilia was called into being. What is most significant here, however, is the complex way in which Dung thinks about the relationships between people and objects.

Hee Wai Siam uses Freudian terminology to point out the frequent occurrence in Dung's fiction of fetishism (and of the sites where the desire this generates is acted out), displacement, simulation, "decreasing yang and increasing yin," and so forth. ${ }^{\left({ }^{3}\right)}$ Were we still to employ Marxist theory, we could describe Hong Kong as a capitalist city with a colonial past, and say that the network of exchange formed by the material and materialisation has spawned a multitude of shadowy demons who make no distinction between human beings and objects. From Dung Kai-cheung's later works we see that "objects" can be a general term for the natural world, the environment of Darwin's origin of species, as well as for all the conditions necessary for creating and being created. If we go a step further and draw a rather far-fetched analogy with the concept of gan wu (感物, gaining inspiration from external reality) in traditional Chinese poetics, we

David Der-wei Wang is Edward C. Henderson Professor of Chinese Literature, Harvard University

In all three titles, the subtitle plays with characters' names: Xuxu and Ruzhen (Vivid and Lifelike), Yaci (Mute porcelain) and Beibei are all characters names. (Trans.)

2. Dung Kai-cheung, "Cecilia," in Mingzi de meigui (The rose of a name), Hong Kong: Pupu gongzuofang, 1997, p. 6.

3. Hee Wai Siam, "Hei qishi de lianwu/(lishi) weiwupi: Dong Qizhang lun" (Fetishism or (historical) materialism of Black Rider: Critical perspective on the works of Dung Kai-cheung), Hong Kong Baptist University, David. C. Lam Institute for East-West Studies, Working Paper Series, No. 64 (June 2007), p. 143. http://www.hkbu.edu. hk/ lewi/WPS/64_Hee.pdf. 
might say that objects trigger emotions, and are the medium that brings about creation. Dung would probably agree with the comment that "shi ren zhi xing, gan wu er zuo" (詩人之興, 感物而作, The poet's talent for evocation arises from his being inspired by external reality). ${ }^{(4)}$

In 1994, Dung won the New Writer's Prize from the Unitas Literary Association in Taiwan for his novella Anzhuozhenni (安卓珍尼, Androgyny). The book was very well received, and became the hallmark of Dung's writing whenever it was discussed. It makes use of a female narrator to extend the dialectics of androgyny and homosexual desire to sexual yearnings and desire outside standard heterosexual relationships. Sex/gender narrative was widespread in the 1990s, and Androgyny, like another prize-winning story, "The double body" (雙身, Shuang shen), appears to be a work wholly in tune with the times. But Dung had other ambitions as well: he wanted to explore how desire and the body revolve between culture and nature and their myriad orientations. The subtitle of the story is "Evolution of a nonexistent species" (Yige bu cunzai de wuzhong de jinhuashi), and the transgender adventures of the main female character run in parallel with the story of her search for the androgynous band-tailed hairy lizard. This lizard is a parthenogenetic female species, which in the process of evolution has managed to rid itself of male dominance and engages in pseudo-sexual congress with its mate, thereby achieving self-fertilisation. The Chinese rendering of the word "androgyny" in the text is thus both a reference to an ambiguous category in the biosphere and an imagined comparison to the female protagonist's sexuality. ${ }^{(5)}$

Dung ranges over a wide variety of phenomena in the biosphere that have either evolved or degenerated, linking them to the complex dimension of human reproductive increase. He deduces from this exercise that the borderline between nature and culture is actually not fixed but shifting, and that "existent" and "non-existent" can refer to features of knowledge and laws as well as to physiology and bio-phenomena. Because of this, his horizons suddenly expand. Dark and bright, true and false, female and male, integration and separation are no longer binary opposites; rather they form derivative relationships of interaction. As a result, the distinction between interiority and exteriority is subject to reconsideration. Homosexuality and heterosexuality are but one aspect of Dung's venture into the evolution of species and the development of culture; he is more interested in considering which miraculous power might have been able to bring this world into being, and in discerning its systems clearly. In the Natural History trilogy, Dung finally tells us that this power, which in the past was attributed to a "creator," is to be found today only in "the fabricator - the writer of fiction."

After the mid-1990s, Dung extended this approach to historical discourse. On the eve of the 1997 "handover" of Hong Kong to China, he published Dituji (The Atlas), seemingly an attempt to re-cast both the past and the present for a Hong Kong about to meet its doom. The book is stylistically an amalgam: true is mixed with false, text with pictures, anecdotes and history are fused together. It is arranged in four sections: theories, cities, streets, and signs. These four sections and the ways in which they are treated are four different kinds of texts, or rather, four sites, which may or may not be inter-connected. The heterogeneous, three-dimensional historical outlook built up like this is naturally very different from linear history. One cannot help smiling to oneself when one sees the glosses provided for the specialised terms cuozhidi (錯置地, misplace), feidifang (非地方, non-place), and duoyuandi (多元地, multitopia), or reads about the origins and development of streetnames such as Kwan Tai Lo, Ice House Street and Aldrich Street. The influence of Italo Calvino, Jorge Borges, and others is clearly visible here, and particular reference is made to Michel Foucault's identification of the characteristics of heterotopia. $\left.{ }^{6}\right)$

Among Dung's other works are "Yong Sheng Jie xingshuai shi" (永盛街興 衰史, The Rise and Fall of Wing Shing Street) and "V cheng fansheng lu" ( V城繁勝錄, Visible Cities: A Chronicle of the Splendour of V City). The former is the history of a fictitious old street in Hong Kong as its fortunes wax and wane. The latter draws its inspiration from Dongjing meng Hua lu (東京夢華錄, Record of Dreaming of Hua in the Eastern Capital) by the Southern Song loyalist Meng Yuanlao, and re-works it to refer to the grandeur that the Hong Kong in Visible Cities once experienced. Whether looking forward or backward, Dung feels an abiding nostalgia for the Hong Kong in which he was born and brought up. He understands, however, that no matter whether Hong Kong is a colony or a Special Administrative Region, its history must be in the hands of others, and it is in the process of being invented - yet the identity of the city has become extraordinarily real. "Fiction is the City of Victoria, and the substance of all cities; and the atlas of a city has to be our own story, which we ourselves augment, revise, embellish, and subvert." (7)

This reminds us of the subtitle of The Atlas, "Yige xiangxiang de chengshi de kaoguxue" (The archaeology of an imaginary city). It is also inspired by Foucault's concept of archaeology. As with the subtitle of Anzhuozhenni, ("Evolution of a non-existent species"), Dung uses the writer's prerogative to unearth - or construct - a life history for Hong Kong. Located as it is at the intersection of many spatial topoi, Hong Kong's origins are somewhat dubious, and whether or not it disappears is unimportant. It does nothing but extend, in the configuration of power, in architectural blueprints, in literature. "It eternally combines the styles of the past, present, and future... . and the dotted line is getting longer all the time, like a story that will never be finished." (8) At that point, Hong Kong had become a metaphor for Dung's imaginary history. By the time he wrote the Natural History trilogy, it had become a metaphor for the creation of his imaginary universe.

\section{Variations in Natural History: Humanised nature and diffracted time}

The Natural History trilogy represents the consolidation of Dung Kaicheung's creative experience. Prior to this, he had produced mainly short stories and novellas, or longer works consisting of several different episodes put together. "Tiyu shiqi" (體育時期, The P.E. period; 2003) has been his only experimental work since "The Double Body" (1997). The focus of this story is sexual/gender politics within a school, but in its subject matter and structure it can hardly be considered a mature work. The Natural History trilogy attracted attention as soon as it came out. As stated previously, the title of the trilogy evokes neither Hong Kong nor

4. Wang Yanshou, in "Lu dian Lingguang fu" (Rhapsody on Lu Lingguang Hall), cites Jiang Yin's discussion of yan zhi (言志, "expressing intent"), gan wu (感物, "being inspired by external reality") and yuan qing, (緣情, originating in emotion), Gudian shixue de xiandai quanyi (Modern commentary on classical poetics), Beijing, Zhonghua shuju, 2009, p. 253.

5. See Mei Jialing's penetrating analysis, "Yuedu 'Anzhuozhenni': cixiong tongti/ nü tongzhi/ yuyan jiangou" (Reading Androgyny. Hermaphrodite/lesbian/linguistic construct), in Xingbie, haishi jiaguo? Wu ling yu ba jiu ling niandai Taiwan xiaoshuo lun (Gender or nation? Fiction in Taiwan from the 1950s to the 1980s and 1990s), Taipei, Maitian chubanshe, 2004, pp. 267 -298.

6. For definitions and discussion of heterotopias, see Michel Foucault, "Of Other Spaces", 1967, http://foucault. info/documents/heteroTopia/foucault.heteroTopia.en.html.

7. Dung Kai-cheung, Dituji: Yige xiangxiang de chengshi de kaoguxue (The atlas: The archaeology of an imaginary city), Taipei, Lianhe wenxue, 1997, p. 97.

8. Ibid., p. 97. 
China (as one might have assumed it would) - instead, it takes its name from the "natural history" that lies outside macro-history. The titles of each part of the trilogy invoke, or are modelled on, Tiangong kaiwu (The Exploitation of the Works of Nature, 1637), by the Ming dynasty writer Song Yingxing, Stephen Hawking's A Brief History of Time: From the Big Bang to Black Holes (1988), and Charles Darwin's The Origin of Species (1859) respectively, and the intention is clearly to set up a dialogue concerning modern intellectual discussion between China and the West.

If the "evolution of a non-existent species" and the "archaeology of an imaginary city" represent two different orientations of Dung's previous work, in recent years the strong rationality and evidence of intellectual enquiry revealed in the Natural History trilogy can be regarded as his focus. This does not mean that Dung has ceased to be concerned about humans and objects, history, and cities, but rather that he is attempting to go further in both of these directions. He wants to explore what lies beneath "evolution" and "archaeology," from bodies to culture to the intellectual pedigree of the universe, and the ethical relevance of the intervention of the intellect and its stimulation of the human condition. This is a huge question, and the serious reader cannot but feel somewhat anxious about the scale of Dung's ambition. But Dung's strategy is never straightforward, and at the same time he tells us that the other side of knowledge - or truth - is nothing but fabrication, that is, fiction. This provides him with a stage on which to demonstrate what he does best: to use the unlimited capacity of narrative to stage the principles involved. The three parts of the Natural History trilogy are the most recent "philosophical novels" to have appeared on the Chinese literary scene.

Although for Dung "evolution" and "archaeology" make up the bulk of the last century's episteme, they are ultimately restricted by the dimensions of time and space. Neither the unilinear historical view implied by the former nor the "consciousness of ruins" (feixu yishi) on which the latter is based adequately explain why universal life is constantly in a state of flux and never stable. (9) Dung prefers to blaze a different trail, and ponder afresh the significance of these fluctuations, which is why he resorts to an epistemology of the kind found in Tiangong kaiwu, in which Man conquers nature and creates his own works in order to achieve his desires, and why he calls for a "plurality" of histories rather than one simple history. The origin that his Origin of Species refers to, rather than a source of authentic purity, is best described as a source with multiple origins, an unprecedented and unrepeatable source, which is eternally recurring.

Basically, Dung is saying that the origin of the universe was creation and what could more closely resemble (fictional) creation than the metaphor of something coming from nothing, of substance emerging from the void. The paradox of Dung's Natural History trilogy is that it is actually a "history of creation" that tells how nature has been "humanised" - how it has moved from being nature as it was at the dawn of time to nature that has become nature through custom and habit.

Part 1 of the trilogy, Works and Creation, presents a narrative in two voices. Against the background of a family's history, Dung looks back at how, from the 1930s to the 1950s and 60s, a generation of Hong Kong people toiled hard to achieve the prosperity that the territory later enjoyed; he then uses the narrator's own experience of growing up in the 1970s to 1990s to point up Hong Kong's continuing prosperity. At first glance Dung appears to be writing a standard family history; however, his method is not to mould his characters so that he can use them to provide a historical framework, but to highlight "people" and "objects," and look at how the themes of birth and creation in (Hong Kong's) history are connected in terms of the process whereby the two either develop in parallel or interact for a particular purpose.

Dung introduces 13 items to illustrate the interaction between men and objects: the radio, telegraph, telephone, lathe, sewing machine, television, car, games console, watch, typewriter, camera, cassette recorder, and book. These items are so common that they have become an organic part of everyday life and living, and it is this very process of mutual invention and of habit turning into nature that the narrator prompts us to recall. This process can be traced from the copy of Tiangong kaiwu owned by his grandfather Dung Fu, and the Wanwu yuanli tujian (萬物原理圖鑑, Illustrated Handbook of the Principles Behind All Things) so assiduously studied by his father Dung Sin Yiu, to the narrator's own generation ("I"), and is seen very clearly in his writing Works and Creation.

This leads us to another voice in the novel - detailing the life of the young girl Xuxu. She is a character written into being by the author, but once shaped, she seems to take on a life of her own and moves from being fabricated to being real, frequently interacting with the author. Moving between two different worlds, the "I" of the narrator also splits into two characters with different personalities, Hei (黑, Black) and the Dictator (獨裁者, Ducaizhe). It is the Dictator who writes the preface to Works and Creation, a book that, he implies, was written by Hei.

In Histories of Time: The Lustre of Mute Porcelain, the Dictator has become the main character, and he and his wife Yaci (Mute Porcelain) have had twin boys, Hua (Flower) and Guo (Fruit). The Dictator happens to meet a young female shop assistant, En'en (Grace), and the two embark on a correspondence about "the infant universe." (10) While this is happening, Hua disappears. Seventeen years later, by which time the Dictator, now paralysed, has retired to the country, an Anglo-Chinese student named Virginia comes to visit him. Together, they write stories, set at some point in the future, when $\checkmark$ City has been inundated, and a girl called Virginia, who has a mechanical clock as a heart and is fated always to be 17 years old, is living alone in a library in the hills. In 2097, a young person called Hua comes to pay a visit...

Dung is ostensibly in disagreement here with the implicit assumption of the title of Hawking's Brief History of Time, and contends that there are multiple histories of time: "Time has no beginning, and no end. History has not been negated, it just means that there will never again be a single history, but many different kinds: complex, intersecting, diverging, replicated, and contrasting. Thus there is always the potential for escape, the possibility of a breakthrough." (11) Situated among all these time-threads is the novelist known as the Dictator. The negative counterpart of the novelist Hei in Works and Creation, he is stubborn and selfish, but knows his own limitations: "I am a symptom, and if it is worth writing about me at all, that is my only significance." (12) The Dictator experiences for himself the subtleties of history/time in the celestial bodies of the universe, and is con-

9. Dung Kai-cheung, "Cong 'Tiangong' dao 'Kaiwu': yizuo chengshi de jiancheng" (From natural creation to human invention: The building of a city), talk given at a seminar on "The Consciousness of City in Literature" at the Eighth Hong Kong Literature Festival (2010), published in Zi Hua 26, July 2010.

10. The dictator says to En'en, "You tell me you have never been travelling. I believe that you will surely have the chance to go one day in the future. Now, I can only take you on an imaginary journey in the world of literature. Maybe we will go to Japan, or a tropical island. But our real destination is time. Time, which belongs to all possible worlds, which diverges and yet is parallel. Such times as these I call the infant universe. I have always thought that the very act of writing fiction creates an infant universe, the possibility of creating people." Dung Kai-cheung, Shijian fanshi:Yaci zhi guang, vol. 2, Taipei, Maitian chubanshe, 2007, p. 374.

11. Dung Kai-cheung, ibid., vol. 2, p. 420

12. Dung Kai-cheung, ibid., vol. 1, p. 26. 
stantly pondering the possibility of a breakthrough. Ironically, however, he is trapped by his own thoughts, and is stranded paralysed at home. It is only through his interactions with the three female characters in the novel - his wife Yaci (ethical time), the young shop assistant En'en ("infant universe" time), and the mixed-race graduate student /robot Virginia (political/scientific time) - that he can gain even a limited comprehension of the divergent meanings of time. Dung once again uses his favourite spatial images, such as the library (as in "A brief history of the silverfish"), the icerink ("Takeshi Kitano on the ice-rink"), and the old quarters of cities (The Atlas), as coordinates of different time dimensions. Dealing as it does with such topics as linearity and intertwinement, belief and irony, action and futility, the book is vividly allegorical.

Works and Creation imagines a history of people/objects in Hong Kong, presenting fiction as a sort of craft, a creative force, and it contains frequent strokes of genius. By contrast, the Dung Kai-cheung of Histories of Time: The Lustre of Mute Porcelain seems to have been affected by the Dictator about whom he is writing. He starts to wallow in self-indulgence, and the writing in the 600,000-character Histories is surprisingly monotonous. Dung knows his limitations, however, and The Apprenticeship, the first volume of Origin of Species: Beibei is Reborn, although still a monumental work, is much livelier when it comes to how the scenes are controlled and how the plot and ideas are organised. The novel no longer draws on analysis of the abstraction of universal time, but realistically portrays a year in the life of a female student called Zhi (芝) after she graduates from university. It reports her romantic escapades, but focuses chiefly on her further education through a reading group she joins, and her participation in the group's activities.

Another reason that this novel is so readable is that Dung uses the format of the reading group's discussions as an effective means of introducing his principle interests in recent years, and the sources on which his research and thinking have been based. Since its subtitle is The Apprenticeship, its didacticism is of course totally justifiable. Maybe this is why it is more successful than any of Dung's earlier fiction at drawing us into his world.

\section{From evolution to ethics: The Apprenticeship}

The Apprenticeship is the story of Zhi, a recent university graduate who has come to the town of Sai Kung, in Hong Kong's New Territories. Her approach to life is very idealistic, but she has no clear goals. She makes friends with a group of people from similar backgrounds, and thus begins a year's "apprenticeship." Her studies include intellectual challenges, political participation, and the tribulations of desire. She meets Zhong (中, Middle), a charming singer-songwriter, and shares a flat with her; she falls in love with a man called Zhih (志) ${ }^{(13)}$ whose aspiration is to serve society; she becomes the object of his friend Jiao's unspoken affection; and with her colleagues in the reading group she takes part in demonstrations to try to save the old streets. As the story unfolds, Zhi discovers that Zhong is actually male, and that her stance on social issues is also a charade. When a somewhat ambiguous affection develops between her boyfriend Zhih and Zhong, the plot of the novel suddenly takes a different turn. Zhi tells Hei (the novelist in Works and Creation) about her experiences; later, she will have a romance with Hei's son Hua.

The relationships between Zhi, Zhih, Zhong, and Jiao bring to mind themes such as androgyny and the evolutionary split between humans and objects that appear in Dung's earlier stories such as Androgyny and "The Double Body." Zhi is obviously a re-incarnation of the character
Beibei in "The P.E. Period." Dung's constant concerns of urban consciousness and a sense of social responsibility permeate the book. The Apprenticeship gives a detailed account of the 12 meetings of the reading group over the past year. The members of the group take turns to recommend a book and introduce it. Their reading and discussions produce an abundance of different opinions and arguments, and the tension this produces is far greater than that deriving from the four-cornered relationship between Zhi, Zhih, Zhong, and jiao.

The books the group reads are Wilhelm Meister's Apprenticeship (Goethe), Farewell, My Books (Kenzaburo e), Blindness (José Saramago), poems by Fernando Pessoa, Walden (Thoreau), The Human Condition (Hannah Arendt), On Late Style (Edward Said), The Raft is Not the Shore (Thich Nhat Hanh and Daniel Berrigan), Rabelais and his World (Mikhail Bakhtin), and Evolution and Ethics (Thomas Huxley). This is a pretty weighty list, covering many aspects of literature, philosophy, politics, religion, history, and science. Dung is not averse to showing off his erudition in his writing, but he is also striving to package the discussions between the members of the reading group as extremely noisy occasions. A single voice concealed in this uproar very soon gets drowned out by the polyphonic dialectics, (14) and we begin to wonder exactly what point Dung is trying to make, among the heterogeneous mix of books and arguments.

We may remember that in his earlier book Histories of Time: The Lustre of Mute Porcelain, Dung made great use of science and metaphor to explore various time dimensions during the formation of the universe, and Man's search for the possibility of a breakthrough. Each of the chapter headings in the novel bears witness to this: "Black holes," "Supernovas," "General relativity," "The theory of everything," and so on. If physics is the line of reasoning behind Histories of Time, then ethics has become the focus of The Apprenticeship. In the former, the Dictator devotes himself to the "infant universe," but ultimately finds himself unable to move, trapped in a net that he himself has constructed; in Histories of Time, he has been replaced by a group of ordinary young men and women acting out the mysterious or unbearable dimensions of life. Dung's intentional implication here is that the true meaning of his Natural History trilogy may have started with the thoughts of a single individual, but that ultimately it has had to progress to interactions between individuals, between Man and the world, and the universe.

The 12 books introduced by Dung may strike one as rather unfashionable. Not a single standard post-modernist reader figures on the list, whereas some "outmoded" classics such as Walden and Evolution and Ethics do make the grade. But when confronted with the modern recycling of theories, which may appear avant-garde but is actually conservative, it is clear that Dung intends to take exactly the opposite direction. He is not only trying to use late, "untimely" reading to break out of the present situation, he also wants to explore the possibility of a revival of the importance of the humanities in a future world - and whether "reviewing the old" really can help us gain insights into the new.

The most important book on the list in The Apprenticeship has to be Wilhelm Meister's Apprenticeship, written in 1795-96 by Goethe (17491832). There is indeed something Goethean about the powerful thesis and profound longing in the Natural History trilogy, and The Apprenticeship, as

13. Zhi and Zhih should in fact both be romanised as "Zhi"; an " $h$ " has been added to distinguish between the two (Trans.).

14. See "Xiaoshuo shi jiangou shijie de yizhong fangfa: Liang Wendao duitan Dong Qizhang" (Fiction is one way of constructing the world: Liang Wendao in conversation with Dung Kai-cheung), INK, no. 79, 2010, pp. 56-57. 
its title implies, is further proof of the work's homage to Wilhelm Meister's Apprenticeship. Goethe's novel tells the story of Wilhelm, the son of a merchant, who has no wish to follow in his father's footsteps, and instead attempts to pursue his ideals in the world of art. He travels around with a band of travelling actors, encountering many different facets of human experience, until he meets Lothario, a liberal-minded aristocrat, and is deeply influenced by the whole-hearted devotion to others with which Lothario lives his life. Wilhelm leaves the troupe of actors and, having decided to work for the benefit of mankind, joins Lothario's secret organisation, the "Society of the Tower."

The warp and weft of Wilhelm Meister's Apprenticeship are a young man's coming of age and his experiences and thoughts as he does so. The interweaving of the two provides a sampler of social change, and the novel has always been considered the original Bildungsroman. But the time about which Goethe wrote was the time at which he himself lived, and a turning-point for modern European history. In the twenty-first century, Dung Kai-cheung has taken a fresh look at the Bildungsroman and turned his attention to something he feels deeply about: with the passing of the modern and post-modern ages, we have reached another turning-point in history - where should we go from here? Since there is nothing ahead, he wants to look back. In his imitation of Goethe's novel, Dung has put an abundance of interesting contrasts into The Apprenticeship, and has applied his considerable skills to the re-creation of the novel form. From the early capitalist period of Europe to the late capitalist period in Hong Kong, from Wilhelm Meister's male inspiration to Zhi's female inspiration, from Mignon's ambiguous sexuality to Zhong's androgyny, from the secret "Society of the Tower" to the reading group, from a travelling drama troupe to experimental theatre, Dung has deliberately imposed an inverted image onto Goethe's novel, 200 years later. If readers are surprised by the lengthy speeches in The Apprenticeship, they have only to look at the long-winded dialogues between the characters in Wilhelm Meister to understand why they are there. But this kind of "repetition" is not merely a mechanical copy; it is a misplacement that is similar in form but different in substance, fission that spreads to every level. ${ }^{(15)}$ What remains unchanged is the constant challenging by the author of ideas, society, and human life.

Of all the modern literature and philosophers discussed by the reading group, Dung probably has the greatest admiration for Kenzaburo e and Hannah Arendt. Arendt's exposition of her ideas arouses fierce debate in the reading group, and Dung also uses the voices of other writers to enter into dialogue with her. Arendt's teacher and lover Heidegger, for example, considers the meaning of being from the angles of "being and time" (Sein und Zeit), and thus makes Arendt's ideal political community of citizens more flexible; the concept of the carnivalesque, proposed by Bakhtin in his identification of modes, praises the carnival politics of the body and of the ordinary people, and both combines with and contests Arendt's politics of reason; Thoreau's transcendentalism starts from his own moral uplift, but his quest to find and hold fast to what is good leads to acts of civil disobedience; even figures in the religious world such as Thich Nhat Hanh have to constantly adjust the balance between the contribution they make when moving in society and the redemption they can attain when they leave it.

Some readers might wish to point out that even if these debates are very noisy, it is still easy to detect that it is Dung himself who is operating from many angles. He gives only vague descriptions of what his characters look like - it is not their personalities that matter in their interactions, but rather their standpoints. But compared to the high-brow arguments in His- tories of Time, The Apprenticeship is much more accessible when it comes to handling relations between people, and in its critiques of responsibility, violence, humiliation, repentance, and love.

This is all the more evident as Dung carefully weaves together the content of the twelve meetings of the reading group and other elements of the plot, and it becomes much more noticeable that he is using one thing as a metaphor for another. The discussions about ideas and actions echo the involvement of the members of the reading group in trying to save the old streets of Sai Kung and protect its large trees, while the chapters about the real "me" and the mask, the public and the private, disorder and order, also contrast with the sexual entanglements of the three main characters. But Dung does not include Darwin's The Origin of Species among the books read by the group; instead he chooses Huxley's Evolution and Ethics, and this is a clear indication that he views nature and ethics as interacting both internally and externally. It is only at the end of the novel, after Zhi has struggled through a year of study, that the test of real life will begin for her. To find out what happens next, we will have to wait for the final volume of the trilogy.

\section{Rethinking the Bildungsroman, redefining humanity}

The Bildungsroman is an important strand of modern Chinese fiction. It is in just such a framework of ideas that we can make out the changes, or lack of change, in Dung's The Apprenticeship and other examples of the modern Chinese Bildungsroman. In the May Fourth and revolutionary periods, young people concentrated on the fate of the nation and their own subjective emotional relationships; the development of fiction and the vision of society that the writers projected were inextricably linked. Dung's fiction, by contrast, is not burdened by any "obsession with China," and even less by a unilinear view of history. His characters may have a double body, or they may be replicas or robots. In a (future) age where it seems that nothing at all has happened, their principal activities are falling in love (regardless of gender), reading and discussing books, and taking part in noisy but ineffective environmental protests. Readers hoping to find the blood and tears of a great age in the books are destined to be disappointed: it is Dung Kai-cheung's idea of fiction that takes precedence, and they may find his books long and tedious, definitely not "moving."

In the light of the various critiques to which Wilhelm Meister's Apprenticeship has been subjected, we need to ask: do the characteristics of Dung's Apprenticeship reveal loftier aims and show clearly that he has substituted a broader thought framework for the overall national interest? Or is it that, restricted by the post-colonialist, post-society situation in Hong Kong, all he can do is to "make something out of nothing"? Perhaps his oscillating between these two extremes simply highlights Dung's subjective position as a Hong Kong writer in the new century - a position that is "empty at the core."

What we should be able to glean from Dung is that the political/fictional discourse of the past hundred years has reached the point where it has started all over again. Not only can the old Bildungsroman teach us nothing, it has by now been reduced to a kind of literary hard labour. Our generation does not want to learn about Mao's never-ending revolutionary campaigns or deconstructionist games like those of the "Yale gang of four," (16) but about Hannah Arendt's politics of the modal citizen, Bakhtin's

15. On the complex meanings of "repetition," see Gilles Deleuze, Difference and Repetition, trans. Paul Patton, New York, Columbia University press, 1995; J. Hillis Miller sees "repetition" as an important aesthetic principle in the writing of fiction, in Fiction and Repetition, Cambridge, Harvard University Press, 1982, Chapter 1. 
politics of the body, and Kenzaburo e's ethical politics of everyday life. And if fiction is to be a mark of "learning," it must abandon its slavish adherence to realism and become an arena for ideological debate on paper. What Arendt calls "inventive action" can only develop in a site that oscillates between two extremes and is also "empty at the core."

But to get back to the point. The reader still feels that something is missing in The Apprenticeship. There is no doubt that Dung is a single-minded (and autocratic) writer, but he is too serious, and is always earnestly trying to teach us something. In my view, as it oscillates between evolution theory and ethics, the novel is not robust enough to meet the demands of aesthetic expression. Dung has made the point that poetry can be produced spontaneously where the discourse of thought is at its most precise. From the standpoint of Chinese poetics, we can also ask if there is an issue around "gan wu" (being inspired by external reality) that needs to be addressed in addition to the "kai wu" (開物, exploiting external reality) debate. At the climax of The Apprenticeship, Dung re-affirms the redemptive and transcendent power of love. The emotional problems of his characters are indeed quite complex, and his descriptions of sexual love are quite provocative, but the writing always seems to be contrived and not entirely natural.

In addition, the books read by the reading group are foreign, and the group's discussions on the whole have little immediate relevance to time and space. This may be because the characters are situated in Hong Kong and, consciously or unconsciously, are keeping their distance from the history and knowledge of a cultural or political "China." It is not up to me, of course, but if the reading group were to continue in existence, it might be a good idea to consider some further items. They might include the debates on aesthetics of Zhu Guangqian, Li Zehou, Cai Yi and others in the late 1950s, as to whether nature is transformed by Man (人化, ren hua) or transforms Man (化人, hua ren), and whether history is "cumulative" or an "invention." Having read Wilhelm Meister's Apprenticeship, the members of the group might also take a look at Caizhu de ernümen (Children of the Rich), by Lu Ling, a young leftwing writer (aged 19 when he wrote it); analogies can be drawn between the two books with regard to such aspects as emotional expression and revolution, thought and action, theatre and life. Lu Ling's revolutionary novel has a modernist flavour, and it contains much of interest, from its standpoint to its form. And with regard to the similarities and differences between the qing (affection) found in the Chinese classics and the ai (love) that has emerged in post-May Fourth writing, maybe the reading group should be required to take another look at Dream of the Red Chamber.

A wave of new Bildungsroman has been surging through modern Chinese fiction, and both sides of the Straits have seen the publication of new works in the genre by writers such as Li Yongping's Da he jin tou (The End of the River), Su Tong's He'an (The Boat to Redemption), Wang Anyi's Qimeng shidai (The Age of Enlightenment) and Lin Bai's Zhi yijiuqiwu (To 1975). But Dung, a new force suddenly emerging from Hong Kong, is capable of outshining them all. Whether in its exploration of the depths of the intellect or its examination of the ethical motives of fiction, The Apprenticeship is a truly remarkable work, and I believe that the following three points are particularly noteworthy.

First, although since the end of the last century fiction has been searching for a breakthrough in the way historical consciousness is handled, as Dung Kai-cheung has pointed out, it still mostly revolves around the "consciousness of ruins." It is not by chance that Mainland novels such as The Age of Enlightenment and To 1975 are set against the backdrop of the Cultural Revolution. Writers find it impossible to let go of the ruthless history sym- bolised by the Cultural Revolution and the countless scars it left. When writers look back and make critical and deconstructionist noises, there is some insight to be gained, but Dung wants to go further. His history is devoted not to the past, but to the future; it is not constrained by the rise or fall of states, but looks far ahead to the evolution of the universe. In this way, time really does become an unrestricted space, and promises can change all kinds of possibilities. Dung emphasises thought and knowledge as action, not ideology, under the compulsion to broaden our field of vision.

With "beginning," rather than "ending," now being the key word in his narrative, Dung proceeds in a very logical manner to inject new life into the imagination of the new century. But his "beginning" does not derive from simple development theory or ontology; it is the point where natural creation (創造, chuangzao) and fictional creation (創作, chuangzuo) intersect. What is more, "beginning" is not necessarily the first point in time to be reached; it can also be attained later by moving back in time. The last book read by the reading group in The Apprenticeship is Said's On Late Style. Dung's characters state repeatedly that "late" does not refer to the ending of natural, physiological time, but to an untimely and unexpected emergence of ideas and style. That is why the last chapter of the novel is entitled "Later than too late, a new beginning." The sequence of time falls apart and recombines, and the organic totality of everything is called into question. It is not hard to see why Dung, writing after the post-modernist age, has modelled his novel on the Bildungsroman of Goethe, a pre-modernist.

For Dung, the importance of fictional narrative lies in the hope that there will be a return of "post-historical" humanism. May Fourth humanism is now far behind us, and the revived discourse of humanism in China since the 1980 s addresses only events that happened in the remote past. The reason why the battle-cry of "Oh humanity!" (Ren, a! Ren) (17) and the campaign to "reconstruct the spirit of humanism" were so short-lived was actually that they did not come up with the capital for reconstruction. A pre-requisite for large-scale construction is large-scale demolition. We need to understand Man as a work in progress, continually creating and being created, moving from subjective existence to artificial intelligence, from the crossing of physiological lines to the inventions of physics and on to ethical behaviour, multiplying and dividing, always carrying the task on, with no end-point - only then will a renewal of the humane be possible. Only in such a setting does Man, as he is born and grows old, sings and weeps, moves forward and comes to a halt, craft this magnificent, Goethean "natural history."

Now, after The Apprenticeship, Dung Kai-cheung's writing will need to make a new beginning. If Goethe's shade still haunts him, maybe he will be reincarnated in his imagination not as Wilhelm Meister, but as Faust. Hong Kong has never been very interested in literature, let alone writing like Dung's. But in Dung, Hong Kong has acquired something very remarkable. Everything acquires symbolic significance, and becomes impossible to imagine - such is the power of literature. Moving from nature to exploitation of its works, from nothing to something, radiating out from one small place to the whole world - the existence of Hong Kong has confirmed the necessity of fabrication, and the need for people like Dung.

\section{Translated by Caroline Mason}

16. The four critics Paul de Man, J. Hillis Miller, Geoffrey Hartman, and Harold Bloom all taught at Yale in the 1970s, and introduced the theory of post-constructionism, which later became the bulwark of US deconstructionism.

17. Title of a novel by Dai Houying, published in English as The Stones in the Wall (Trans.). 